\title{
Probiotics in poultry: modes of action
}

\begin{abstract}
This paper reviews recent advances on the use and mode of action of probiotics (direct-fed microbials) in poultry. The addition of probiotics to the diet has been found to improve growth performance and feed conversion in broilers, and egg mass, egg weight and egg size in layers. The mode of action of probiotics in poultry includes (i) maintaining normal intestinal microflora by competitive exclusion and antagonism; (ii) altering metabolism by increasing digestive enzyme activity and decreasing bacterial enzyme activity and ammonia production; (iii) improving feed intake and digestion; and (iv) neutralizing enterotoxins and stimulating the immune system.
\end{abstract}

Keyword: Broilers; Direct-fed microbials; Lactobacillus; Layers; Modes of action; Performance; Probiotics 